\title{
Decision Dilemmas for Adaptation to Sea Level Rise: How to, when to?
}

\author{
$\mathrm{Oz}_{\text {Sahin }}{ }^{1}$, Sherif Mohamed ${ }^{1}$ \\ ${ }^{1}$ School of Engineering, Griffith University, Gold Coast, Queensland, Australia \\ o.sahin@griffith.edu.au, s.mohamed@griffith.edu.au
}

\begin{abstract}
This paper is part of ongoing research designed to develop a dynamic model for assessing the vulnerability of waterfront properties to sea-level rise (SLR), and to evaluate adaptation options. SLR is one of the best recognized effects of projected climate change within recent literature, and is expected to continue for centuries. Increased storm surge height, due to SLR, may place many coastal properties in danger of erosion and inundation, and millions of people living near the sea may be forced to relocate. If SLR is a fact, decision makers will need to have better tools to understand the extent and timing of coastal hazards. Considering the complexity and dynamic nature of coastal systems interacting and changing over time, this research focuses on modeling temporal and spatial variations of coastal flooding in assessing the vulnerability of these systems to SLR.
\end{abstract}

Keywords - Decision-making, adaptation, dynamic modelling, flooding, SLR, vulnerability.

\section{INTRODUCTION}

There exists a general consensus amongst scientists that the Earth's climate is significantly and inevitably changing. The Intergovernmental Panel on Climate Change (IPCC) informs us that the warming of the climate system is now unequivocal, based on observations of increases in global average air and ocean temperatures, widespread melting of snow and ice, and rising sea level [1].

Sea level rise (SLR) is one of the most recognized possible impacts of this anthropogenic global climate change in the literature. It is estimated that the globalmean sea level may rise between 0.18 and $0.59 \mathrm{~m}$ by 2100 [2]. A new semi-empirical analysis, published after the conclusion of the IPCC Fourth Assessment Report (4AR), suggests an even higher range of 0.5 to $1.4 \mathrm{~m}$ by 2100 [3].

At these estimated rates, SLR will not pose an immediate threat to coastal areas; however, a higher sea level will provide a higher base for storm surges to build upon. Thus, storm surges occurring in conditions of higher mean sea levels will enable inundation and damaging waves to penetrate further inland, increasing flooding, erosion and subsequent impacts on built infrastructure and natural ecosystems [4].

SLR is expected to continue for many centuries, even if Greenhouse Gas (GHG) concentrations are stabilised at relatively low levels $[5,6]$. As a result, SLR will exacerbate the vulnerability of coastal populations and ecosystems via the permanent inundation of low-lying regions, extensions of inland episodic flooding, increased beach erosion, and saline intrusion of aquifers [7]. Such physical impacts may result in socio-economic impacts along the coastal zone, including loss of property and coastal habitats, as well as the loss of tourism, recreation and transportation functions. Consequently, SLR will intensify the stress on coastal zones where adaptive capacities of natural and social systems have been weakened.

As a considerable amount of human activity and population growth takes place in coastal areas, it is already well recognised that SLR will have profound implications for many coastal populations and the systems upon which they depend [8]. Existing near-coastal populations, within $100 \mathrm{~km}$ of a shoreline and within 100 $\mathrm{m}$ sea level, are estimated at 1.2 billion people, with an average density nearly 3 times higher than the global average density [9].

With concern for the consequences of SLR growing, it is essential to develop and implement new methodologies that will assess the vulnerability of coastal systems to climate change; these methods will provide fundamental support to enable effective policy responses that reduce climate-change-related risks [10]. Numerous studies have focused on assessing coastal vulnerability at a national and global scale. However, few regional scale comprehensive vulnerability assessment studies, which are required by local stakeholders designing adaptation strategies at the local level, are available [11, 12].

\section{PROBLEM DEFINITION}

It is imperative that societies respond, sooner rather than later, to SLR to reduce adverse impacts and to improve adaptive capacity. Therefore, we need to understand the impacts of SLR, how to manage a response system, and how to plan our cities. Once this has been achieved, the longer term process of adaptation can be planned more effectively.

However, designing and applying a robust and flexible method to assess present and future vulnerabilities to SLR, and the need to identify and analyse adaptation options for reducing vulnerabilities, are challenging issues in both vulnerability and adaptation research.

The identification and application of correct adaptation options is a difficult process due to the uncertainties in future climate change projections. Therefore, urgency surrounds the development of an adequately flexible and well-structured method. Through its use, the most timely and best available vulnerability 
information will be provided for the design of more effective adaptation strategies and better management plans, and to reduce the adverse effects of SLR [13].

In light of the above observations and studies, and in line with the need for a regional scale analysis, this research focuses on assessing the vulnerability of present and future waterfront properties and populations, in coastal areas, to SLR and storm surge events. The research also examines and evaluates alternative adaptation options to reduce the adverse effects of SLR in the selected study area.

\section{Study Area}

The city of the Gold Coast is selected for case study analyses. This city, like many major cities situated on the coastline of Australia, is threatened by natural hazards, mainly storm tides. It is a low-lying coastal city where many of the residential areas are filled to the 1:100 year flood level [14]. The city is located in south-east Queensland, Australia, and spans across $1402 \mathrm{~km}^{2}$, featuring more than $270 \mathrm{~km}$ of navigable waterways and $70 \mathrm{~km}$ of coastline [15]. The population of the Gold Coast increased from 214,949 in 1986 to 524,667 persons in 2007; it is expected to increase to 886,700 residents in the year $2031[16,17]$.

From 2001 the Gross Regional Product increased from A $\$ 9.7$ billion to A $\$ 15.6$ billion in 2008; it is projected to further increase to A $\$ 17.3$ billion by 2011 . The area is an extremely popular tourist destination, attracting 82,000 tourists and A \$12.1 million expenditure daily [18].
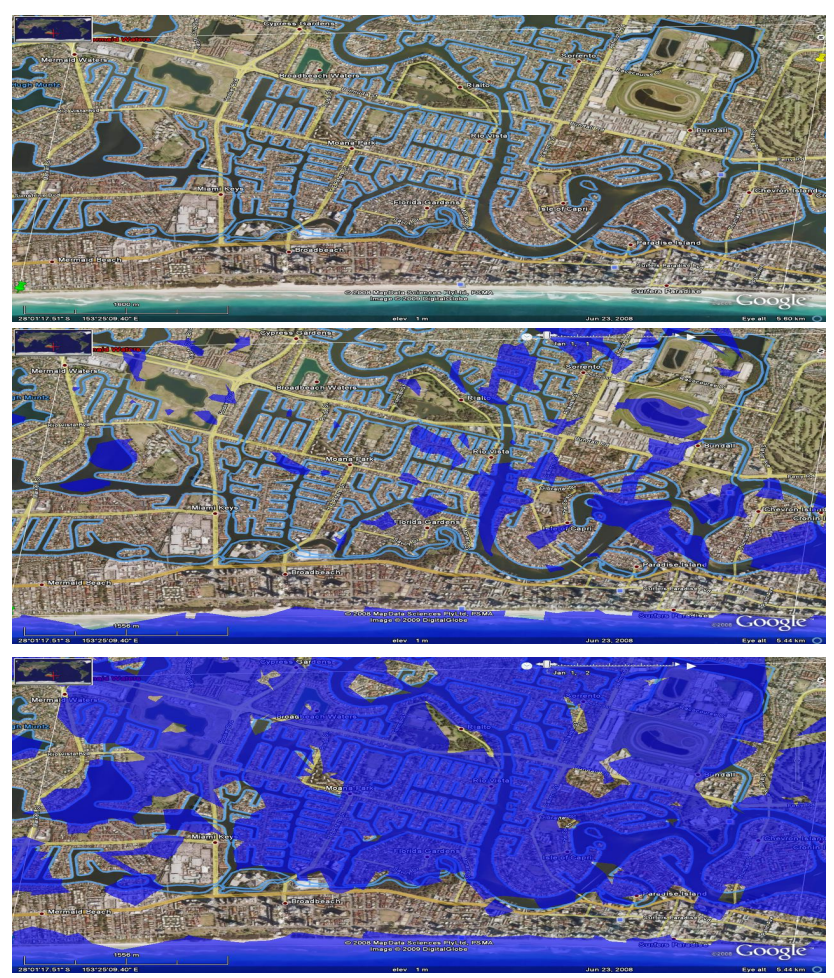

Fig. 1. A Segment of the Study Area
The study area covers a diverse range of features, including sandy beaches, estuaries, coastal lagoons and artificial waterways. Thus, it is highly vulnerable to SLR. Fig. 1, generated using Google-Earth, illustrates the implication of SLR $(1 \mathrm{~m}-2 \mathrm{~m})$ on a segment of the study area. The top picture shows the current condition, whilst the middle and bottom pictures show the condition under 1-metre and 2-metres SLR, respectively. The overall goals of this research are: (a) to assess the present and future vulnerability of the Gold Coast's waterfront properties and coastal populations to SLR and storm surge events, based on various climate and socio-economic scenarios and projections; and, (b) to identify and evaluate adaptation options for coastal areas in order to develop coping strategies for altering climatic condition scenarios. The research, therefore, addresses the following questions:

1. What is the present vulnerability in the study area in terms of the number of residential properties and the population within the $1 / 100$ year flood level?

2. How vulnerable is the study area to future SLR and associated storm surges (number of residential properties, their value and people at risk)?

3. What are the potential physical (inundation, flood and storm surge damage) and socio-economic (people at risk and properties, loss of properties) impacts of SLR and storm surges on the study area?

\section{APPROACH}

The ultimate goal of vulnerability assessment is to produce recommendations on actions to reduce vulnerability [13]. It includes both present and future vulnerability assessments and available adaptation options. Two general types of assessment approaches are described in the literature: impact-led and vulnerabilityled. The impact-led approach begins with the climate system scenarios and moves through the biophysical impacts towards socio-economic assessment, mainly focusing on potential long-term impacts of climate change [19]. The vulnerability-led approach commences at a local scale by addressing the potential socio-economic responses to climate change, focusing on adaptation, with stakeholder involvement [20].

It is desirable to merge these two approaches in order to address both the short and long-term risks posed by SLR. Mindful of this, the conceptual framework proposed for this research is based mainly on UNDP Adaptation Policy Frameworks for Climate Change [21] and UNEP'S Handbook on Methods for Climate Change Impact Assessment and Adaptation Strategies [22]. The current study is an attempt to merge both approaches so that a flexible model can be developed that addresses both short and long-term vulnerability assessment issues.

Vulnerability in this study is defined as people-at-risk and loss of residential property, due to exposure to SLR and related storm surges. Therefore, the research focuses on natural and socio-economic systems that are already vulnerable to climate variability; their current conditions 
are analysed, then these systems, under various scenarios, are reanalysed to identify how climate variability will affect the already troubled systems, over time.

\section{A. Assessment Tools}

The traditional modelling approach focuses on either temporal or spatial variations, but not both [23]. Coastal systems or processes are complex and dynamic in nature, having many feedbacks and dependencies that change over time. Consequently, in the current study, both the temporal and spatial variations of coastal processes are focused on, together. Such modelling highlights the vulnerability of the systems to SLR and storm surges. To achieve this outcome, two modelling techniques are combined:

- System Dynamics (SD), and

- Geographical Information Systems (GIS).

SD, created by Professor Jay W. Forrester, is a powerful methodology and computer-based simulation modelling technique for understanding the behaviour of complex systems over time. It deals with internal feedback loops and time delays that affect the behaviour of the entire system (Fig. 2). GIS is used for geospatial data management and analysis, image processing, map production, spatial modelling, and visualization. The GIS approach has been widely used in vulnerability and impact analyses, especially in many coastal vulnerability assessments, because of its capability to analyse spatial data [24-29].

However, GIS, like SD, has its own strengths and weaknesses. While having strong capabilities for modelling the spatial dimensions of the real world, GIS has difficulties in handling temporal dimensions.

By considering their weaknesses and strengths, a combination of the SD and GIS approaches would provide the potential to address temporal and spatial problems concurrently. Some researchers have coupled SD and GIS to enhance the temporal and spatial aspects of these two approaches. For example, Ruth and Pieper developed model for a coastal process [30], Ahmad and Simonovic

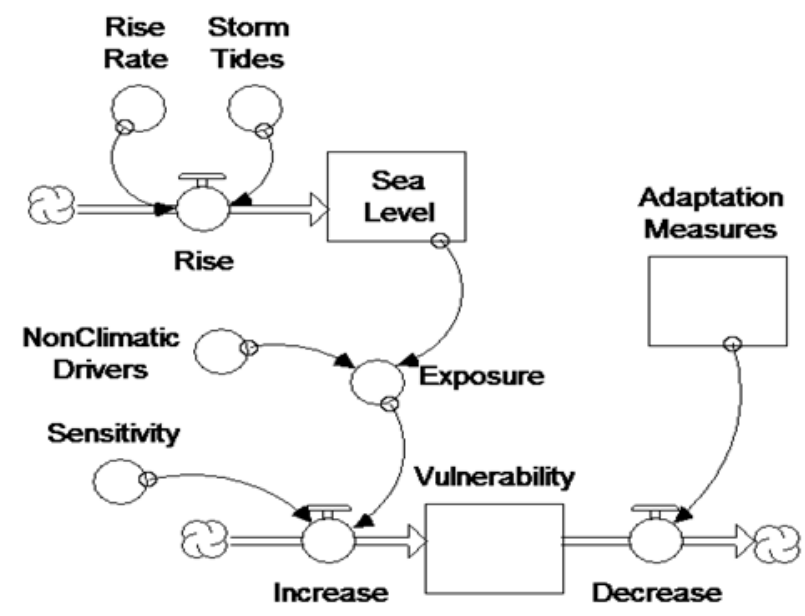

Fig. 2. A simple 'Stock and Flow Diagram' - modelling vulnerability.

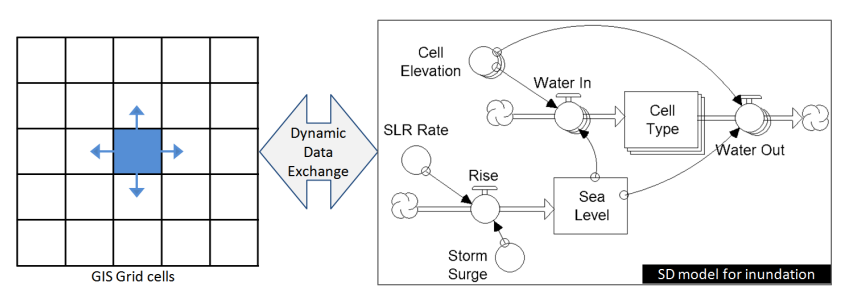

Fig. 3. Conceptual framework of SD-GIS coupling

coupled SD and GIS to capture space-time interaction in overland flood modelling [23], and Ford built a model in which nitrogen flows are simulated for 16 cells within a catchment [31]. Thus the advantages of SD and GIS can be combined in a dynamic model, while eliminating their shortcomings (Fig. 3).

Importantly, temporal and spatial information can be exchanged between SD and GIS by linking them through a dynamic data exchange [13]. While GIS provides spatial information to the $\mathrm{SD}$, the $\mathrm{SD}$ provides temporal information to the GIS by detecting changes in spatial features over time. As a result, the model dynamically captures temporal and spatial changes by obtaining and processing temporal data from the SD and spatial data from the GIS through a dynamic data exchange. Thus, the dynamic nature of coastal processes and their interactions can be captured in time and space. Due to its ease of use, Microsoft Excel is being employed for automatic data exchange between the two models .

\section{B. Vulnerability Assessment (VA)}

Undoubtedly, the SLR will also cause an increase in the level of the hazard zones. Depending on the rate of SLR, an area that is now subject to a $1 / 100$ year flood risk may, in time, face more frequent flood events or become permanently inundated. As a result, the boundary of the coastal flood plain will continue to shift inland over time.

The degree to which coastal land is at risk of flooding from storm surges is determined by a number of morphological and meteorological factors, including: coastal slope, and wind and wave characteristics [32]. Additionally, spatial dependency is a key concept for understanding and analysing spatial events. According to Tobler, the first law of geography is that everything is related to everything else, but near things are more related than distant things [33]. Generalizing, we can state that most of the occurrences, natural or social, will involve a relationship that depends on distance. What does this principle imply? Namely, that if the proximity of a property to the coast increases or decreases, so too would the risk to which it is exposed also rise or fall, due to the SLR.

As previously mentioned, the study area has extensive flood plains, with many residential areas located within the 1/100 year flood level [14]. Exceeding this flood level and/or increasing the frequency of the occurrence of extreme events, due to the changing climate, may put people and properties at risk in these low-lying areas.

Consequently, local governments have taken steps to 
develop and implement various adaptation policies in order to increase the adaptive capacity of their communities. However, there is a need to measure the effectiveness of these policies. In assessing the capacity of society to adapt to climate change so as to project future vulnerabilities, it is instructive to look at the effectiveness of the adaptation policy under current climatic conditions [34]. Thus, the VA starts by analysing current conditions in the study area to provide a reference map with which to compare future conditions. In other words, firstly, we identify those properties/areas that are already under stress to SLR and related hazards, and then we continue to assess how future SLR may apply additional stress to these already troubled systems.

The critical vulnerability of waterfront properties to coastal storms (in the short term) and SLR (in the long term) works through flooding. Therefore, the VA focuses on people and residential properties in the study area that are already facing flood risks. For the current VA, two indicators are selected:

1. Population within the $1 / 100$ year flood level, and

2. Number of residential properties within the $1 / 100$ year flood level

The population and the properties within a $3 \mathrm{~km}$ stretch from the coast become the socio-economic vulnerabilities of the system to be mapped. This assessment will provide comprehensive information about the area and the residents at risk of flooding. GIS has been employed for a rapid quantitative assessment of current conditions in terms of the two above-listed indicators.

Increased flood risk associated with storm surges is one of the primary impacts of SLR on low-lying coastal areas. These areas, depending on the rate of SLR, will provide an elevated base for a storm surge. It is most likely that they will face increased flooding before becoming permanently inundated due to increased flood levels.

For the future VA, the research considers only coastal flooding resulting from SLR and storm surges. The extent and timing of the coastal flooding and its impacts are assessed in terms of two more indicators, under various scenarios, as summarised below. These indicators are:

1. Population at risk over time due to coastal flooding, and

2. Property at risk due to inundation and coastal flooding.

A dynamic model, developed by combining GIS and $\mathrm{SD}$, has been employed for the comprehensive vulnerability analysis covering both temporal and spatial aspects of the risk posed by coastal flooding. GIS will provide data to the SD model, such as elevation, population and property survey data; a cell based SD model will be used to calculate changes in key indicators, over time, showing their interactions with key variables, and then feedback will be provided to the GIS for mapping.

Three SLR scenarios are considered in this research: the IPCC lower and upper range projections (including $10-20 \mathrm{~cm}$ potential contribution from the Greenland and
Antarctica ice sheets) and Rahmstorf's estimation [3], together with additional local adjustments. Thus, while the lower $(0.5 \mathrm{~m})$ and mid range $(1.0 \mathrm{~m})$ scenarios match approximately to the relative SLR projections (the IPCC projection for global SLR, plus the CSIRO projection for local subsidence), the higher range $(1.5 \mathrm{~m})$ scenario combines the local subsidence with the global SLR projection proposed by Rahmsorf [3].

\section{EXPECTED OUTCOMES}

Coastal regions are highly vulnerable to climate change. Therefore developing and implementing effective adaptation options are crucial for their future development. However, there is uncertainty in the timing, duration, spatial location and extent of SLR and storms. So, while the probability and magnitude of a particular flood event, that may occur within the next 100 years, can be estimated, it is not possible to say when exactly this will happen.

The complexity that arises from climate change, coastal systems and their interactions in space and time can easily overwhelm the ability of decision makers to thoroughly investigate the outcomes of adaptation alternatives. The dilemmas confronting decision makers are: how and when to adapt to SLR. Determining how and when specific actions should be taken is not a simple decision, due to the uncertainty in the timing and the magnitude of the SLR impacts. To facilitate these decisions, policy makers require credible scientific data and information.

By considering the uncertain nature of projected changes in climate and addressing these dilemmas, this research intends to provide a dynamic model for a comprehensive current and future vulnerability assessment of coastal areas, focusing on changes in sea level. The model will assist decision makers to identify and evaluate effective adaptation alternatives for reducing climate change impacts.

Significant characteristics of the model are that:

- The model is flexible and modular, therefore other elements effecting coastal systems can be integrated in time, as needed.

- It is dynamic in terms of capturing feedbacks and dependencies changing over time.

- It takes into account the spatial characteristics of the study area.

\section{LIMITATIONS}

This research considers only impacts from inundation and coastal flooding due to storm surges and SLR. All other impacts, such as flooding due to heavy precipitation, are disregarded.

Additionally, non-tidal artificial waterways that are disconnected from the tide by locks and weirs, or have no connection, are excluded. 


\section{REFERENCES}

[1] Solomon, S., et al., "Summary for policymakers", in Climate Change 2007: The Physical Science Basis. Contribution of Working Group I to the Fourth Assessment Report of the Intergovernmental Panel on Climate Change 2007, pp. 1-18.

[2] Meehl, G.A., et al., "Global climate projections", in Climate Change 2007: The Physical Science Basis. Contribution of Working Group I to the Fourth Assessment Report of the Intergovernmental Panel on Climate Change. Cambridge, UK and New York, NY, USA: The IPCC. 2007.

[3] Rahmstorf, S., "A semi-empirical approach to projecting future sea-level rise", Science, vol. 315 , no. 5810, pp. 368370, 2007.

[4] Pearce, K., et al., "Climate change in Australia technical report 2007". 2007.

[5] Nicholls, R.J. and J.A. Lowe, "Benefits of mitigation of climate change for coastal areas", Global Environmental Change, vol. 14, no. 3, pp. 229-244, 2004.

[6] Church, J.A., et al., "Changes in sea level", in The Scientific Basis. Contribution of Working Group I to the Third Assessment Report of the Intergovernmental Panel on Climate Change. Cambridge, U.K. and New York, NY, USA: The IPCC. 2001.

[7] Mclean, R.F., et al., "Coastal zones and marine ecosystems", in Climate Change 2001: Impacts, Adaptation, and Vulnerability: Cambridge, UK and NY, USA, 2001.

[8] Brooks, N., J. Hall, and R. Nicholls, Sea-level rise: coastal impacts and responses. Berlin: The German Advisory Council on Global Change (WBGU), 2006.

[9] Small, C. and R.J. Nicholls, "A global analysis of human settlement in coastal zones", Journal of Coastal Research, vol. 19, no. 3, pp. 584-599, 2003.

[10] Mcfadden, L., R. Nicholls, and E. Penning-Rowsell, Managing Coastal Vulnerability. Burlington: Elsevier, 2006, 283.

[11] Torresan, S., et al., "Assessing coastal vulnerability to climate change: comparing segmentation at global and regional scales", Sustainability Science, vol. 3, no. 1, pp. 4565, 2008.

[12] Cooper, M.J.P., M.D. Beevers, and M. Oppenheimer, "The potential impacts of sea level rise on the coastal region of New Jersey, USA", Climatic Change, vol. 90, no. 4, pp. 475-492, 2008

[13] Sahin, O. and S. Mohamed. "Vulnerability assessment of waterfront residential properties to climate change", in proc. Fifth International Conference on Construction in the 21st Century (CITC-V), 2009, pp. 178-185.

[14] Betts, H., "Flood damage analysis using GIS at Gold Coast City Council", Australian Journal of Emergency Management vol. 17, no. 1, pp. 33-37, 2002.

[15] GCCC, Facts and figures. [Accessed: 2 December 2008];http:/www.goldcoast.qld.gov.au/t standard.aspx?PI $\mathrm{D}=255$.

[16] Queensland Government, "Queensland Government population projections to 2056: Queensland and statistical divisions, 2008 edition". 2008 Queensland Government: Brisbane, Australia.

[17] ABS, Regional Population Growth, Australia, 2006-07. [Accessed: 27 November 2008]; http://www.abs.gov.au/AUSSTATS/abs@.nsf/mf/3218.0/.
[18] GCCC, Gold Coast City Economic Profile. [Accessed: 20 November 2008];

http://businessgc.com.au/index.php?page=economic-quickfacts.

[19] Dessai, S. and M. Hulme, "Does climate adaptation policy need probabilities?", Climate Policy, vol. 4, no. 2, pp. 107128, 2004.

[20] Carter, T.R., et al., "New assessment methods and the characterisation of future conditions ", in Climate Change 2007: Impacts, Adaptation and Vulnerability. Contribution of Working Group II to the Fourth Assessment Report of the Intergovernmental Panel on Climate Change. 2007: Cambridge, UK. p. 133-171.

[21] Lim, B., et al., Adaptation policy frameworks for climate change. Cambridge: Cambridge University Press, 2004.

[22] Feenstra, J.F., et al., "Handbook on methods for climate change impact assessment and adaptation strategies". 1998, UNEP - United Nations Environment Programme.

[23] Ahmad, S. and S.P. Simonovic, "Spatial system dynamics: New approach for simulation of water resources systems", Journal of Computing in Civil Engineering, ASCE, vol. 18, no. 4, pp. 331-340, 2004.

[24] Al-Jeneid, S., M. Bahnassy, and S.N.M.E. Raey, "Vulnerability assessment and adaptation to the impacts of sea level rise on the Kingdom of Bahrain", Mitigation and Adaptation Strategies for Global Change, vol. 13, no. 1, pp. 87-104, 2008.

[25] Gravelle, G. and N. Mimura, "Vulnerability assessment of sea-level rise in Viti Levu, Fiji Islands", Sustainability Science, vol. 3, no. 2 pp. 171-180, 2008.

[26] Lathrop, R.G. and A. Love, "Vulnerability of New Jersey's coastal habitats to sea level rise and American Littoral Society". 2007, Grant F. Walton Center for Remote Sensing \& Spatial Analysis Rutgers University New Brunswick, NJ, USA.

[27] Szlafsztein, C.F. and H. Sterr, "Climate change, sea-level rise and coastal natural hazards: A GIS-based vulnerability assessment, State of Pará, Brazil", Journal of Coastal Conservation, vol. 11, no. 1, pp. 53-66, 2007.

[28] Hennecke, W.G. and P.J. Cowell, "GIS modeling of impacts of an accelerated rate of sea-level rise on coastal inlets and deeply embayed shorelines", Environmental Geosciences, vol. 7, no. 3, pp. 137-148, 2000.

[29] Poulter, B. and P.N. Halpin, "Raster modelling of coastal flooding from sea-level rise", International Journal of Geographical Information Science, vol. 22, no. 2, pp. 167 $182,2008$.

[30] Ruth, M. and F. Pieper, "Modeling spatial dynamics of sealevel rise in a coastal area", System Dynamics Review, vol. 10, no. 4, pp. 375-389, 1994.

[31] Ford, A., Modelling the environment: An introduction to System dynamics modelling of environment systems. Washington DC, USA: Island Press, 1999, 402.

[32] Klein, R.J.T. and R.J. Nicholls, "Coastal zones ", in Handbook on Climate Change Impact Assessment and Adaptation Strategies. 1998, United Nations Environment Programme and Institute for Environmental Studies Amsterdam and Nairobi.

[33] Tobler, W.R., "A computer movie simulating urban growth in the Detroit Region", Economic Geography, vol. 46, no. 2, pp. 234-240, 1970.

[34] Scheraga, J.D. and A.E. Grambsch, "Risks, opportunities, and adaptation to climate change", Climate Research, vol. 11, pp. 85-95, 1998. 